\title{
Aggressive Mature Natural Killer Cell Neoplasms: from Disease Biology to Disease Manifestations
}

\section{Margarida Lima*}

Department of Hematology, Laboratory of Cytometry, Hospital de Santo António, Centro Hospitalar do Porto, Multidisciplinary Unit for Biomedical Investigation, Portugal

\begin{abstract}
Nature killer (NK)/T cell lymphoma, nasal type, and aggressive NK-cell leukemia are rare tumors with higher prevalence in Asia, Central and South America, which are etiologically related to the Epstein Barr virus (EBV). Proteins encoded by EBV genes and non-coding viral RNAs expressed on the infected cells are involved in immune deregulation and cell transformation and lymphomagenesis occur as a consequence of multiple oncogenic events. Complex chromosomal abnormalities are frequent and loss of chromosomes 6q, 11q, 13q, and $17 p$ are recurrent aberrations. In accordance, many genes are differentially expressed, often due to gene deletion, mutation or methylation. These include, among others, tumor suppressor genes and oncogenes, as wells as genes involved in cell signal transducer pathways, cell survival and apoptosis, cell cycle, cell motility and cell adhesion, as well as in cell communication through cytokine networks. Consequently many biochemical pathways are affected in NK-cell neoplasms, which could contribute to cancer development and progression, as well as to disease manifestations. This review focuses on the molecular and biochemical mechanisms by which EBV induces NK-cell lymphomagenesis, disrupting genes and molecules involved in crucial biological processes. Improving the knowledge in this subject will help to better understand the disease biology and clinical manifestations and to develop new treatment approaches for the NK-cell malignancies.
\end{abstract}

Keywords: NK-cell neoplasms; NK/T-cell lymphoma; Nasal-type; Aggressive NK-cell leukemia; Extranodal lymphomas; Epstein Barr virus; Oncogenesis; Lymphomagenesis; Angioinvasion; Vascular destruction; Hemophagocytic syndrome

Abbreviations: AIM1: Absent in Melanoma-1; ANKCL: Aggressive NK-cell Leukemia; ATG5: Autophagy related 5; ATM: Ataxia Telangiectasia Mutated; ATR: ATM Rad3-related; AURKA: Aurora kinase A; BBC3: BCL2-Binding Component 3; BIM: Bcl-2-like Protein 11; BIRK5: Baculoviral Inhibitor of apoptosis Repeat-containing 5; BLIMP1: B-lymphocyte-Induced Maturation Protein 1; BM: Bone Marrow; BTAK: STK15 or Aurora kinase A (AURKA); CAM: Cell Adhesion Molecules; CCL2: C-C Motif Chemokine Ligand Type 2 (MCP-1); CCL3: C-C Motif Chemokine Ligand Type 3 (MIP-1alpha); CCL4: C-C Motif Chemokine Ligand type 4 (MIP-1beta); CCL5: C-C motif chemokine ligand type 5 (RANTES); CCL8: C-C motif chemokine Ligand type 8 (MCP-2); CCL18: C-C Motif Chemokine Ligand Type 18 (PARC); CCL19: C-C Motif Chemokine Ligand Type 19 (ELC); CCNA2: Cyclin-A2; CCR5: C-C Motif Chemokine Receptor Type 5 (CD195); CD11b: Integrin alpha M Complement Receptor Type 3; CD49b: Integrin alpha 2 alpha 2 Subunit of VLA-2 Receptor; CD49d: Integrin alpha 4 alpha 4 Subunit of VLA-4 Receptor; CDK: CyclinDependent Kinases; CGH: Comparative Genomic Hybridization; CHK: Checkpoint Protein Kinases; C-KIT: Cellular homolog of the feline sarcoma viral oncogene v-KIT; CLPD-NK: Chronic Lymphoproliferative Disorders of NK-cells; CPP32: Apoptosis-Induced Cysteine Protease 32; CTL: Cytotoxic T lymphocytes; CXCL1: C-X-C Motif Chemokine Ligand Type 1 (IL-18); CXCL9: C-X-C Motif Chemokine Ligand Type 9 (MIG); CXCL10: C-X-C Motif Chemokine Ligand Type 10 (IP-10); CXCL11: C-X-C Motif Chemokine Ligand Type 11 (IP9); CXCL12: C-X-C Motif Chemokine Ligand Type 12 (SDF-1); CXCR1: C-X-C Motif Chemokine Ligand Receptor Type 1 (CD181); CXCR3: C-X-C Motif Chemokine Ligand Receptor Type 3 (CD183); CYR61: Cysteine-rich Angiogenic Inducer 61; DEFB: Defensin Beta; EBV: Epstein-Barr Virus; ELC: EBI1 Ligand Chemokine (CCL18); FasL: Fas Ligand (CD95L); FGF: Fibroblast Growth Factor; FLIP: FLICE-like Inhibitory Protein; FOX: Forkhead Family of Transcription Factors; FOXO: Forkhead Transcription Factors of the O class; FOXO3:
Forkhead Transcription Factors of the O class type 3; HACE1: HECT Domain and Ankyrin Repeat Containing E3 Ubiquitin Protein Ligase 1; HS: Hemophagocytic Syndrome; ICAM-1: Intercellular Adhesion Molecule -1 (CD54); IFN: Interferon; IGF: Insulin-like Growth Factor; IGIF: Interferon-Gamma Inducing Factor (IL-18); IL: Interleukin; IL18BP: IL-18 Binding Protein; IL-6R: Interleukin 6 Receptor; IP10: IFN-Gamma-Inducible Protein 10 (CXCL10); Jak: Janus kinase; K-RAS: v-Ki-ras2 Kirsten Rat Sarcoma Viral Oncogene Homolog; LACE1: Lactation Elevated 1; LFA: Leukocyte Function Adhesion Molecule; LFA-1: Lymphocyte Function Molecule Type 3 (CD11a); LFA-3: Lymphocyte Function Molecule Type 3 (CD58); LMP: EBVEncoded Latent Membrane Protein; MCP-1: Monocyte Chemotactic Protein-1 (CCL2); MCP-2: Monocyte Chemotactic Protein-1 (CCL8); MIB1: Mindbomb E3 Ubiquitin Protein Ligase 1 also known as Ki67; MIG: Monokine Induced by Gamma Interferon (CXCL9); MIG: Monokine Induced by IFN-Gamma (CXCL9); MIP: Macrophage Inflammatory Protein; MIP-1alpha: Macrophage inflammatory protein-1alpha (CCL3); MIP-1beta: Macrophage Inflammatory Protein-1beta (CCL4); MMP: Matrix Metalloproteinases; MYC: v-myc Myelocytomatosis Viral Oncogene Homolog; NFкB: Nuclear Factor $\kappa B$; NK: Natural Killer; NKTCL: NK/T Cell Lymphoma; NOTCH: Notch Homolog translocation-associated; PAR: Plasminogen Activator Receptor; PARC: Pulmonary and Activation-Regulated PARC (CCL18);

*Corresponding author: Margarida Lima, Department of Hematology, Laboratory of Cytometry, Hospital de Santo António, Centro Hospitalar do Porto Rua D Manuel II, s/n 4099-001 Porto, Portugal, Tel: 351-22-2077500; Fax: 351-22600480; E-mail: mmc.lima@clix.pt, margaridalima@chporto.min-saude.pt

Received November 25, 2013; Accepted December 13, 2013; Published December 15, 2013

Citation: Lima M (2013) Aggressive Mature Natural Killer Cell Neoplasms: from Disease Biology to Disease Manifestations. J Blood Disorders Transf 5: 182 doi: 10.4172/2155-9864.1000182

Copyright: (c) 2013 Lima M. This is an open-access article distributed under the terms of the Creative Commons Attribution License, which permits unrestricted use, distribution, and reproduction in any medium, provided the original author and source are credited. 
PDGF: Platelet-Derived Growth Factor; PDGFR: Platelet-Derived Growth Factor Receptor; PDGFRA: Platelet-Derived Growth Factor Receptor Alpha; PI3K: Phosphatidylinositol 3 Kinase; PI9: Protease Inhibitor Type 9; PKB: Protein Kinase B; POPDC3: Popeye Domain Containing 3; PRDM1: PR Domain Zinc Finger Protein 1; PREP: Prolyl Endopeptidase; PTEN: Phosphatase and Tensin Homolog; PUMA: p53 Upregulated Modulator of Apoptosis; RNA: Ribonucleic acid; SDF-1: Stromal Cell-Derived Factor-1 (CXCL12); STAT: Signal Transducers and Activators of Transcription; STK15: also known as BTAK or Aurora Kinase A (AURKA); TGF: Transforming Growth Factor; Th: T Helper; Th1: T Helper Type 1; Th2: T Helper Type 2; TIA-1: T-cell-Restricted Intracellular Antigen; TNF: Tumor Necrosis Factor; TNFAIP3: Tumor Necrosis Factor Alpha-Induced Protein 3 also known as A20; TNFR: Tumor Necrosis Factor Receptor; TP53: Tumor Protein p53; TP73: Tumor Protein p73; TRAF: TNF Receptor Associated Factor; uPAR: Urokinase-Type Plasminogen Activator Receptor; VCAM-1: Vascular Cell Adhesion Molecule Type 1 (CD106); VEGF: Vascular Endothelial Growth Factor; vIL-10: viral homologue of Interleukin 10; WHO: World Health Organization.

\section{Introduction}

Natural killer (NK) cell neoplasms are rare diseases that are much more prevalent in Central and South America and Eastern countries for reasons that are not completely clear. They comprise a limited spectrum of Epstein Barr virus (EBV)-related neoplasms [1-21], two of which were recognized by the World Health Organization (WHO) classification as distinct entities [22]: extranodal NK/T Cell Lymphomas, Nasal Type (NKTCL) [23] and Aggressive NK-Cell Leukemia (ANKCL) [24]. The histological hallmark of these aggressive tumors is a polymorphic neoplastic infiltrate with extensive angiotropism, vascular destruction and tissue necrosis.

There are two variants of NKTCL, the nasal and extranasal forms $[1,10,14,25]$. The nasal form primarily affects the upper aerodigestive trait, although dissemination may occur in advanced disease stages; the extranasal variant is frequently disseminated at the time of the diagnosis, most patients having multiple organs and tissues involved. Bone Marrow (BM) involvement at the diagnosis is uncommon $[4,26]$, whereas the Hemophagocytic Syndrome (HS) is frequent, especially in patients with advanced disease [27].

Aggressive NK-cell leukemia is very rare and has a fulminant clinical course [2,28-32]. Patients often present with systemic symptoms, BM involvement, pancytopenia, hepatosplenomegaly and abnormal liver function, and frequently develop HS, multiorgan failure and disseminated intravascular coagulation [33-39].

The oncogenic properties of the EBV have been recognized for almost fifty years, when the virus was discovered inside cultured Burkitt's lymphoma cells [40]. In Europe and North America, the primary neoplasms associated with EBV are B-cell lymphomas and nasopharyngeal carcinomas, probably reflecting the primary targets of EBV infection, which are B cells and tonsillar epithelial cells [41,42]. NK-cell lymphomagenesis results from multiple oncogenic events occurring in EBV-infected NK-cells, which involve proteins encoded by EBV genes and non-coding viral RNAs expressed on the infected cells. The oncogenic events include deletion, mutation or methylation of genes involved in cell signal transducer pathways, survival and apoptosis, cycle progression and division, motility and adhesion, as well as in cytokine networks.

We have recently reviewed the epidemiological and diagnostic features of the NKTCL and ANKCL [18]. Herein, we review the molecular and biochemical mechanism involved in oncogenesis and disease manifestations of these aggressive NK-cell neoplasms.

\section{Mechanisms involved in NK-cell oncogenesis}

Although the pathogenesis of the NK-cell tumors remains poorly understood, some insights have been gained in the recent years concerning the mechanisms involved in oncogenesis and disease progression [43-45]. In accordance, disruptions of molecular mechanisms and cell signaling pathways involved in NK-cell maturation may lead to the development of NK cell malignancies [43]. Multiple genes involved in crucial biological processes are differentially expressed in NK-cell neoplasms, often due to deletions, mutations or abnormal methylation patterns (Table 1). However, in NK-cell tumors, where necrosis usually associates with tissue infiltration by mesenchymal cells and reactive inflammatory cells, it is often difficult to directly attribute the molecular alterations to the tumor cells without confirming it with biochemical or immunohistochemical studies.

\section{Chromosomal and genomic abnormalities}

Despite the difficulties in obtaining representative NKTCL biopsy samples, several cytogenetic, genetic and genomic studies, using Comparative Genomic Hybridization (CGH) and loss of heterozygosity techniques, were performed [45-53]. Although genetic abnormalities specific for NKTCL and ANKL have not yet been identified, complex chromosomal abnormalities occur in a large fraction of cases, abnormalities of the chromosome 6 being the most frequent [46]. Cytogenetic abnormalities are seen in most patients and include pseudodiploidy in about half, hyperdiploidy in about one third, and hypodiploidy in about a tenth of cases [46]. Frequent cytogenetic aberrations are loss of chromosome $6 \mathrm{q}, 11 \mathrm{q}, 13 \mathrm{q}$, and $17 \mathrm{p}$ and a common deletion of $6 \mathrm{q}$ in the target area $6 \mathrm{q} 21-25$ was identified [46,52]. An array-based CGC analysis revealed clear genetic differences between ANKCL and extranodal NKTCL, suggesting that these are two distinct diseases [53]. In accordance, recurrent aberrancies in NKTCL are gain of $2 \mathrm{q}$, and losses of 6q16.1-q27, 11q22.3-q23.3, 5p14.1-p14.3, 5q34-q35.3, 1p36.23-p36.33, 2p16.1-p16.3, 4q12, and 4q31.3-q32.1, whereas those recurrently found in ANKCL are gain of $1 \mathrm{q}$ and losses of 7p15.1-p22.3 and 17p13.1 [53]. Most of the implicated genes have not been identified so far.

\section{Tumor suppressor genes and oncogenes}

Two 6q21 regions are frequently deleted in NKTCL [54]. One of these regions includes POPDC3 (Popeye Domain Containing 3), PREP (Prolyl Endopeptidase), PRDM1 (PR Domain Zinc Finger Protein 1, also known as BLIMP1, B-lymphocyte-induced Maturation Protein), AIM1 (Absent in Melanoma-1) and ATG5 (Autophagy related 5), whereas the other region includes LACE1 (Lactation Elevated 1) and FOXO3 (Forkhead Transcription Factors of the O Class Type 3) genes. Most of these genes are down-regulated in NK-cell neoplasms and are therefore considered as possible tumor-suppressor genes, whereas other act as oncogenes.

Tumor suppressor genes: FOXO3 (6q21) and PRDM1 (6q21) were identified as tumor suppressor genes having a potentially critical role in the biology of NKTCL and ANKCL as re-expression of PRDM1 and FOXO3 genes in NK-cell lines suppress NK-cell proliferation [55,56].

FOXO are class $\mathrm{O}$ forkhead family of transcription factors (FOX), which share the ability to be inhibited and translocated out of the nucleus on phosphorylation by proteins such as AKT/PKB (Protein 
Citation: Lima M (2013) Aggressive Mature Natural Killer Cell Neoplasms: from Disease Biology to Disease Manifestations. J Blood Disorders Transf 5: 182. doi: 10.4172/2155-9864.1000182

Page 3 of 10

\begin{tabular}{|c|c|c|c|c|}
\hline Function of the involved genes & Functional status in NK-neoplasms & Gene & Genetic aberration & References \\
\hline \multirow{8}{*}{ Tumor suppressor genes } & \multirow{8}{*}{ Down-regulated } & PRDM1 & 6q21-q22.1 (del6q21) & {$[54-56,64-66]$} \\
\hline & & FOXO3 & $6 q 21$ & [55-63] \\
\hline & & ATG5 & $6 q 21$ & {$[54,66]$} \\
\hline & & AIM1 & $6 q 21$ & {$[45,54,66]$} \\
\hline & & HACE1 & $6 q 21-23$ & {$[45,48,55]$} \\
\hline & & TNFAIP3 (A20) & $6 q 21-23$ & [55] \\
\hline & & TP53 & $17 p 13.1$ & [82] \\
\hline & & TP73 & $1 p 36.3$ & [84] \\
\hline \multirow{8}{*}{ Cell signaling transducing pathways } & \multirow{8}{*}{ Up-regulated } & STAT3 & $17 q 21$ & {$[96,97]$} \\
\hline & & JAK2 & $9 p 24$ & {$[45,48]$} \\
\hline & & IL-10 & 1q31-q32 & {$[111,112]$} \\
\hline & & AKT1/2/3 & $14 q 32.3 / 19 q 13.1 / 1 q 44$ & {$[45,48,54]$} \\
\hline & & NOTCH1 & $9 q 34.3$ & {$[45,101]$} \\
\hline & & B-CATENIN (WNT) & $3 p 22-p 21.3$ & [48] \\
\hline & & PDGFRA & $4 q 11-q 13$ & {$[45,48]$} \\
\hline & & PDGFA/B & $7 p 22 / 22 q 12.3-q 13.1$ & [48] \\
\hline \multirow{6}{*}{ Cell survival en apoptosis } & \multirow{4}{*}{ Down-regulated } & CCND3 & $6 p 21.1$ & [48] \\
\hline & & SERPINB9 (PI9) & $6 p 25$ & {$[132,133]$} \\
\hline & & TNFAIP3 & $6 q 23$ & [48] \\
\hline & & FAS & $10 q 24.1$ & {$[102,103]$} \\
\hline & \multirow{2}{*}{ Up-regulated } & SURVIVIN (BIRC5) & $17 q 25.3$ & [74] \\
\hline & & FASL & 1q23 & {$[102,103]$} \\
\hline Cell division & Up-regulated & AURKA & $20 q 13$ & [101] \\
\hline \multirow{4}{*}{ Angiogenesis } & \multirow{4}{*}{ Up-regulated } & MET or HGFR & $7 q 31$ & {$[45,48]$} \\
\hline & & VEGFR2 & $4 q 12$ & {$[45,48]$} \\
\hline & & VEGFA & $6 q 12$ & {$[45,48]$} \\
\hline & & HIF1a & $14 q 21-q 24$ & {$[45,54]$} \\
\hline
\end{tabular}

Table 1: Major molecular and biochemical mechanisms potentially involved in aggressive mature NK-cell neoplasms.

kinase B) in the PI3K (Phosphatidylinositol 3 kinase) signaling pathway thereby controlling a wide spectrum of biological processes $[57,58]$. FOXO3 triggers for apoptosis through up-regulation of genes codifying for pro-apoptotic proteins, such as BIM (Bcl2-like protein 11) (2q13) [59] and PUMA (p53 up-regulated modulator of apoptosis, also known as BBC3, BCL2-binding component 3) (19q13.3-q13.4) or down-regulation of genes that codify for anti-apoptotic proteins, such as FLIP (FLICE-like inhibitory protein) [60,61]. In addition, FOXO3 signaling links ATM (Ataxia Telangiectasia Mutated) to the p53 pathway following DNA damage [62]. FOXO3 is also involved in protection from oxidative stress by up-regulating antioxidants such as catalase and manganese superoxide dismutase [63]. Deregulation of $\mathrm{FOXO} 3$ activity has been implicated in tumorigenesis in multiple cancers, for instance by an increase in $\mathrm{AKT} / \mathrm{PKB}$ activity resulting from loss of PTEN (Phosphatase and Tensin homolog).

PRDM1 is a repressive transcription factor that is essential for the terminal B-cell differentiation and also plays a pivotal role in the negative regulation of NK-cell activation, by suppressing the release of Interferon (IFN)-gamma, and Tumor Necrosis Factor (TNF)-alpha, and beta through direct binding to conserved regulatory regions [64]. This gene is frequently inactivated in tumor NK-cells by a combination of monoallelic deletion, promoter hypermethylation and mutations resulting in truncated PRDM1 $[65,66]$.

ATG5 (6q21) a gene essential for autophagy, and AIM1 (6q21), a gene implicated in melanoma, may also participate in oncogenesis, as ATG5 and AIM1 transcripts are also markedly reduced in both NK-cell lines and NKTCL tumor cells $[45,66]$.

Down-regulated expression of the TNFAIP3 (tumor necrosis factor alpha-induced protein 3 gene, also know as A20) and HACE1 (HECT domain and ankyrin repeat containing E3 ubiquitin protein ligase 1) suppressor genes, located on 6q21-23, may also play a role in the pathogenesis of NK-cell neoplasms, as both genes are frequently silenced in NKTCL through a combination of deletion and hypermethylation [45,67-69].

TNFAIP3 (6q23) was identified as a gene whose expression is induced by TNF-alpha, which codifies for a zinc finger protein and ubiquitin-editing enzyme, with both ubiquitin ligase and deubiquitinase activities; this protein has been shown to inhibit NFאB (nuclear factor $\kappa \mathrm{B})$ activation and TNF-mediated apoptosis and is involved in the cytokine-mediated inflammatory and immune responses [70,71]. The HACE1 gene (6q21) codifies for an E3 ubiquitin-protein ligase involved in Golgi membrane fusion and regulation of small GTPases, such as Rac1, thereby controlling cell migration $[72,73]$.

Abnormalities of the TP53 and TP73 tumor-suppressor genes have also been described in a significant number of NKTCL cases [45,74-84]

Mutations in the TP53 gene (17p13.1), a well known tumor suppressor gene that codifies for $\mathrm{p} 53$, a protein that causes cells with damaged DNA to arrest at the G1 phase of cell cycle are frequently found in NK-lymphoma cells [74-81]. For instance, in one Asian series of 100 cases of nasal NKTCL, nearly half had TP53 mutations [81]. TP53 gene mutations have been associated with more advanced disease, suggesting a secondary event rather than a triggering mechanism [82].

Methylation of TP73 gene (1p36.3), which codifies for p73, a p53related protein involved in cell cycle arrest and apoptosis has been found in the majority of NKTCL and has been proposed as a biomarker to detect NKTCL involvement and metastasis $[83,84]$.

Oncogenes: Abnormalities of the C-KIT (cellular homolog of the 
feline sarcoma viral oncogene v-kit), MYC (v-myc myelocytomatosis viral oncogene homolog), MAFB (V-maf musculoaponeurotic fibrosarcoma oncogene homolog), K-RAS (v-Ki-ras2 Kirsten rat sarcoma viral oncogene homolog) and $\beta$-catenin oncogenes have been described in a significant number of NKTCL cases [45,74,81,85-92].

The C-KIT proto-oncogene (4q11-q12) encodes a receptor tyrosine kinase (CD117) which is involved in normal hematopoiesis via interaction with the c-KIT ligand. Previous studies in nasal NKTCL performed in Asia revealed a variable frequency of cases with C-KIT gene mutations, depending on the country $[81,85]$

The MYC genes (8q24.21) encode for nuclear phosphoproteins (c-MYC, MYCN, and MYCL) that act as transcription factors to regulate expression of genes involved in cell cycle progression that codify for cyclins, such as CCNA2 (cyclin A2), and CDK (cyclin dependent kinases), such as CDKN1A and CDKN2B. Besides regulating genes involved in cell proliferation, they also control the complex networks of micro-RNAs and apoptosis mediators [86,87]. Although MYC expression appears to be up-regulated in NKTCL lymphoma cells, mutations, amplifications, and translocations of this oncogene have not yet been found [74].

Other studies have suggested that the inactivation of the cell cycle regulatory genes by DNA methylation could also contribute to tumorigenesis [88].

The MAFB gene (20q11.2-q13.1) codifies for MAFB, a transcription factor that plays an important role in hematopoiesis by repressing erythroid-specific genes in myeloid cells. Up-regulation of this oncogene was observed in NKTCL but also in T-cell and B-cell lymphomas $[45,89]$.

The RAS and beta-catenin genes are implicated in various nonhematological cancers, but also in some hematological malignancies.

RAS is a family of related small proteins with GTPase activity, involved in signal transduction. Mutations in specific codons of one of the three RAS genes, H-RAS, K-RAS, and N-RAS, giving rise to constitutively active RAS proteins, are found in a variety of nonhematological tumors, but also in myeloid leukemia [90].

$\beta$ - Catenin, an integral structural component of cadherin-based adherent junctions, exerts a crucial role in a multitude of biological processes. More specifically, $\beta$-catenin interacts with different transcription factors, being the key nuclear effector of canonical WNT signaling in the nucleus. Mutations in the $\beta$-catenin gene (3p21-3p22) resulting in imbalance in the structural and signaling properties of $\beta$-catenin have been implicated in non-hematological cancers, metastasis and angiogenesis [91]. Moreover, constitutive activation of the $\mathrm{WNT} / \beta$-catenin pathway was observed in some hematological malignancies, such as chronic lymphocytic leukemia and mantle cell lymphoma [92].

Mutations of K-RAS and beta-catenin genes were examined in nasal NKTCL from Korea and Japan, using PCR-SSCP followed by direct sequencing. K-RAS and beta-catenin mutations were found in higher incidence in Japan as compared with Korea [81].

\section{DNA repair}

Cellular responses to DNA damage are mediated by a number of protein kinases, including ATM (Ataxia Telangiectasia Mutated), ATR (ATM And Rad3-Related) and CHK (Checkpoint Protein Kinases), which play an important role in DNA repair and chromosomal stability; these two kinase signaling cascades, the ATM-CHK2 and ATR-CHK1 pathways, are activated by DNA double-strand breaks and singlestranded DNA, respectively [93]. Alterations in the ATR gene resulting in an abnormal response to DNA single-strand break repair were also found in NKTCL, suggesting a role in lymphomagenesis [94]

\section{Cell signaling transducing pathways}

The STAT factors (Signal Transducers and Activators of Transcription), are transcription factors activated in response to cytokines or growth factors [95]. They act by a mechanism that requires tyrosine phosphorylation of the STAT proteins, as a result of their association with surface receptors having intrinsic tyrosine kinase activity, or through recruitment of members of the Jak (Janus kinase) family to activated surface receptors (Jak/STAT pathways) [95]. Constitutive activation of STAT factors, such as STAT3, has been shown to play a role in oncogenesis in a large variety of tumors, including NKTCL, this protein being localized in the nucleus of the tumor cells in the majority of the cases $[96,97]$.

Other possible involved signaling pathways include those of the NOTCH (Notch homolog, translocation-associated), the NFkB (nuclear factor $\kappa \mathrm{B}$ ), and the WNT/ $\beta$-catenin [45,98-101].

The NOTCH signal cascade comprises the NOTCH transmembrane protein and their ligands, as well as intracellular proteins transmitting the NOTCH signal to the nucleus [98]. The NOTCH signaling pathway leads to activation of the PI3K (phosphatidylinositol 3 kinase)/PKB and down-modulation of PTEN expression. PI3K/AKT was found to be activated in NKTCL, and nuclear expression of phosphorylated-AKT was observed in the nucleus of the tumor cells in most NKTCL samples [45].

The NFkB, a master regulator that controls the expression of a number of genes, is also known to be activated in EBV-infected cells, through LMP-1 (EBV-encoded latent membrane protein type 1) and/ or TRAF (TNF receptor associated factor) signaling [100]. Signaling by the transcription factor NFKB involves its release from its inhibitor I $\mathrm{B}$, followed by its translocation into the nucleus. RelA, the protein constituting the most abundant form of $\mathrm{NF \kappa B}$, is detected in the nucleus of the neoplastic NK-cells, supporting the activation of this pathway in NKTCL $[45,74]$. In addition it has been disclosed that TNFAIP3 (TNFalpha-induced protein gene), an inhibitor of $\mathrm{NF \kappa B}$, is down-regulated in NKTCL [45]. Surprisingly, the NFkB pathway genes were not included in the NKTCL gene signature in another recent study [101].

Concerning the activation of the $\mathrm{WNT} / \beta$-catenin signaling pathway, mediated by WNT proteins, a group of secreted lipid-modified signaling proteins, nuclear expression of $\beta$-catenin was not observed in the tumor NK-cells, making its significance ambiguous [45].

\section{Cell survival and apoptosis}

The disequilibrium between pro-apoptotic and anti-apoptotic signals probably contributes to the survival of the neoplastic NKcells $[74,102,103]$. In fact, although Fas (CD95) and Fas ligand (FasL/ CD95L) are frequently expressed in NKTCL cells, mutations of the FAS gene are observed in about half of cases, most likely inducing resistance to apoptosis $[102,103]$. These mutations are often frameshift mutations arising in the death domain, leading to Fas proteins that are unable to transduce the apoptotic signal $[102,103]$. More recently, survivin (BIRC5, baculovirus inhibitor of apoptosis repeat-containing 5), an inhibitor of apoptosis frequently involved in tumor oncogenesis, was found to be overexpressed in NKTCL [74]. 


\section{Cell division, chromosome segregation and cytokinesis}

Aurora kinase A (AURKA, also called STK15 and BTAK), is a member of the Aurora/Ipllp family of mitotically regulated serine/ threonine kinases, which are centrosome-associated and play an important role as regulators of chromosome segregation and cytokinesis, a process that ensure that each daughter cell receives the full genetic material $[104,105]$. Previous studies showed that AURKA is overexpressed in NK-cell neoplasms, being involved in the induction of centrosome amplification-distribution abnormalities [101]. In addition, overexpression of AURKA leads to increased degradation of p53, causing down-regulation of checkpoint pathways [106]. All these abnormalities can lead to centrosome amplification, chromosome instability, aneuploidy and propagation of genetic abnormalities, thereby inducing oncogenic transformation.

\section{Angiogenesis}

Angiogenesis is regulated by the coordinated action of various proteins with pro- and anti-angiogenic functions [107]. Pro-angiogenic factors include VEGF (Vascular Endothelial Growth Factor), FGF (Fibroblast Growth Factor), PDGF (Platelet-Derived Growth Factor), IGF (Insulin-Like Growth Factor), TGF (Transforming Growth Factor), CYR61 (Cysteine-Rich, Angiogenic Inducer 61), angiopoietins, and chemokines; anti-angiogenic factors include thrombospondin-1, angiostatin, and endostatin. Matrix metalloproteinases display a dual role in vascular development. $\mathrm{NOTCH}$ signaling affects remodeling of the primary vascular network into functionally and morphologically distinct arteries, veins, and capillaries.

Over-expression of the mRNAs transcribing for CYR61, a secreted protein that promotes the adhesion to endothelial cells, and VEGF, a signaling protein involved in both vasculogenesis and angiogenesis, is found in the vast majority of NKTCL cases by real-time quantitative PCR; expression of the CYR61 and VEGF proteins is detected in lymphoma cells by immunohistochemistry [108]. The expression of VEGF mRNA in NKTCL seems to be far more frequent than that of FGF mRNA, and CD44 expression is also detected in a considerable proportion of cases using immunohistochemistry studies, although these markers can not predict the angioinvasion potentiality of the NKcells [109]. Previous studies that combined gene expression profiling and array-based CGH analyses showed that NKTCL overexpress several genes related to vascular biology, including the PDGFR (Platelet-Derived Growth Factor Receptor) alpha gene (PDGFRA) [45]. These results were also confirmed by immunohistochemistry studies, suggesting that PDGFR is involved in the disruption of the angiogenic pathways observed in NK-cell neoplasms [110].

\section{Cytokine networks}

Cytokines, such as IL-9, IL-10, and IP-10 (IFN-gamma-inducible protein-10, CXCL10), have also been implicated in the pathogenesis of the NK-cell neoplasms [8]. Cytokine production may occur due to the effect of EBV-oncogenic proteins in the lymphoma cells and often act in an autocrine manner, taking an important part in the neoplastic cell proliferation and invasion. BCRF1, an open reading frame of EBV, codifies for a viral protein that exhibits extensive functional homologies with human IL-10, a pleiotropic cytokine with immunosuppressive properties. Previous studies showed that human IL-10 is frequently expressed on NKTCL tumor cells, whereas the expression of viral IL10 (vIL-10) seems to be variable $[111,112]$. In addition, the neoplastic NK-cells often express IL-9 and IL-9 receptors suggesting an autocrine loop [113]. Other genes codifying for cytokines and cytokine receptors that map to regions with recurrent aberrations include the IL-6 receptor (IL6R) (1q21.3) and the TNF receptor (TNFRSF21) (6p12.3) genes [45]

\section{Mechanisms underlying disease manifestations}

NK-cell neoplasms are recognized by their ability to invade the blood vessels and to destroy the tissues, but also to induce an uncontrolled macrophage activation that culminates with the development of the HS. Such disease manifestations are probably related to the chemotaxis and adhesion properties of the neoplastic NK-cells, to the release of cytotoxic proteins, as well as to their ability to produce proteases and Th1 cytokines [114-146] (Figure 1).

\section{Cell motility and tissue invasion}

NKTCL tumor cells were shown to over-express invasionassociated genes and proteins, including those related to proteolysis, cell motility and chemotaxis. These include genes codifying for matrix metallopeptidases and their inhibitors, cathepsins and chemokines, among others [114-129].

Proteolytic enzymes: Tumor invasion and metastasis are facilitated by the up-regulation of various types of proteases, which induce the escape of cancer cells from the primary site, by breaking down the connective tissue and basement membrane, such as metalloproteinases and cathepsins both of which appear to be affected in NKTCL [114-124].

Matrix metalloproteinases (MMP, 1 to 28) are zinc-dependent endopeptidases capable of degrading extracellular matrix proteins, such as collagen and gelatin, being also able to process a number of bioactive molecules and thereby regulating cell growth, migration, invasion and angiogenesis [114,115]. Among them, MMP-2 (Gelatinase A) and -9 (Gelatinase B) have been associated with cancer [116]. The activity of MMP is inhibited by tissue inhibitors of metalloproteases (TIM, 1 to 4) [117]. The unbalance of the expression of MMP and TIMP may contribute to the extensive necrosis observed in NKTCL, as well as to the tendency of these tumors to disseminate locally [120-123]. For instance, on a study in which the expression of MMP-1, -2, -3, -9, $-11,-13$ and TIMP-1 and -2 was evaluated by immunohistochemistry revealed that NKTCL cells and fibroblasts were positive for MMP-1 and MMP-11 in most of the cases, whereas MMP-2, -3 and -9 were expressed in neoplastic cell in between 30 to $65 \%$ of the cases; TIMP-1 was presented mainly in the epithelium and TIMP- 2 was poor expressed of the all cases [120]. Another study revealed that most NKTCL were MMP-9+, expression of MMP-2 being also noted in some cases [121]. In addition, nasal NKTCL usually have a strong expression of MMP-9 as compared to nasal non-NKTCL [122]. NKTCL involving the upper aerodigestive tract over-express MMP-2 and MMP-9 genes as compared to non upper aerodigestive tract cases moreover, the MMP-9 expression is accompanied by an increased expression of UPAR (urokinase-type Plasminogen Activator Receptor) and MMP-2 and MMP-9 expression correlates with a poor prognosis $[121,123]$.

In addition to metalloproteinases, well known to be secreted outside cells, there is increasing evidence that cathepsins (CTS), a group of lysosomal proteases that have a key role in cellular protein turnover, may also play an important role in the development and progression of malignant tumors $[118,119]$. NKTCL cells overexpress CTSB and CTSL, the genes that codify for cathepsins B and L, respectively and reduced expression of cathepsin D in NKTCL seems to be related to autophagic cell death $[45,123,124]$.

Chemokines and chemokine receptors: Chemokines are a group of small (approximately 8 to $14 \mathrm{KD}$ ) structurally related molecules, which 
Citation: Lima M (2013) Aggressive Mature Natural Killer Cell Neoplasms: from Disease Biology to Disease Manifestations. J Blood Disorders Transf 5: 182. doi: 10.4172/2155-9864.1000182

IISSEE DESTRUCTION, ANGIOINVASTON AND TUMOR METASTASTS

\section{TH1-TYPE IMMUNE RESPONSE, RECRUTIMENT OF} NFLAMDATORY CELLS AND MONOCYTEMACROPHAGE ACTIVATION

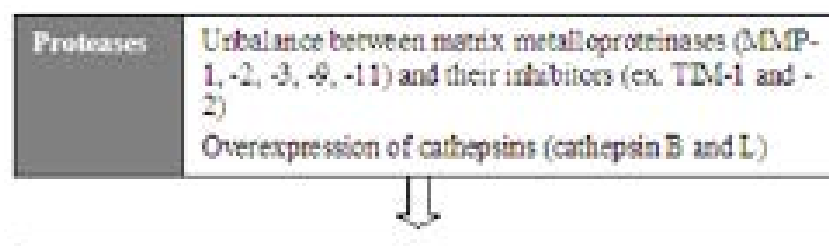

Degnatation of extacellutar mairix groteins.

\begin{tabular}{|c|c|}
\hline & gradation of extacellutar matrix groteins. \\
\hline $\begin{array}{l}\text { Qytchasic } \\
\text { and pro- } \\
\text { apeptose } \\
\text { malecules }\end{array}$ & 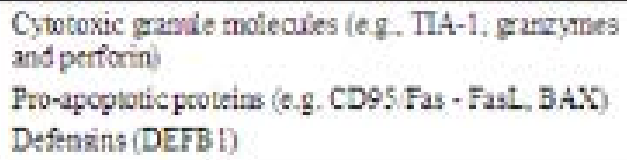 \\
\hline
\end{tabular}

\begin{tabular}{|c|c|}
\hline \multicolumn{2}{|r|}{ Cytccoxiciry and apoptodic cell death } \\
\hline $\begin{array}{l}\text { Coll } \\
\text { anhedion } \\
\text { melcules }\end{array}$ & 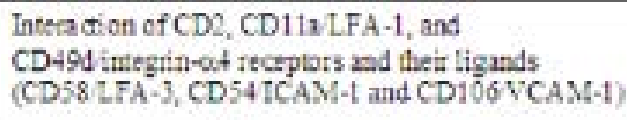 \\
\hline & ए \\
\hline Adnesion & $\begin{array}{l}\text { the NX cells to ocher cells, including the endothelial } \\
\text { cells. }\end{array}$ \\
\hline
\end{tabular}

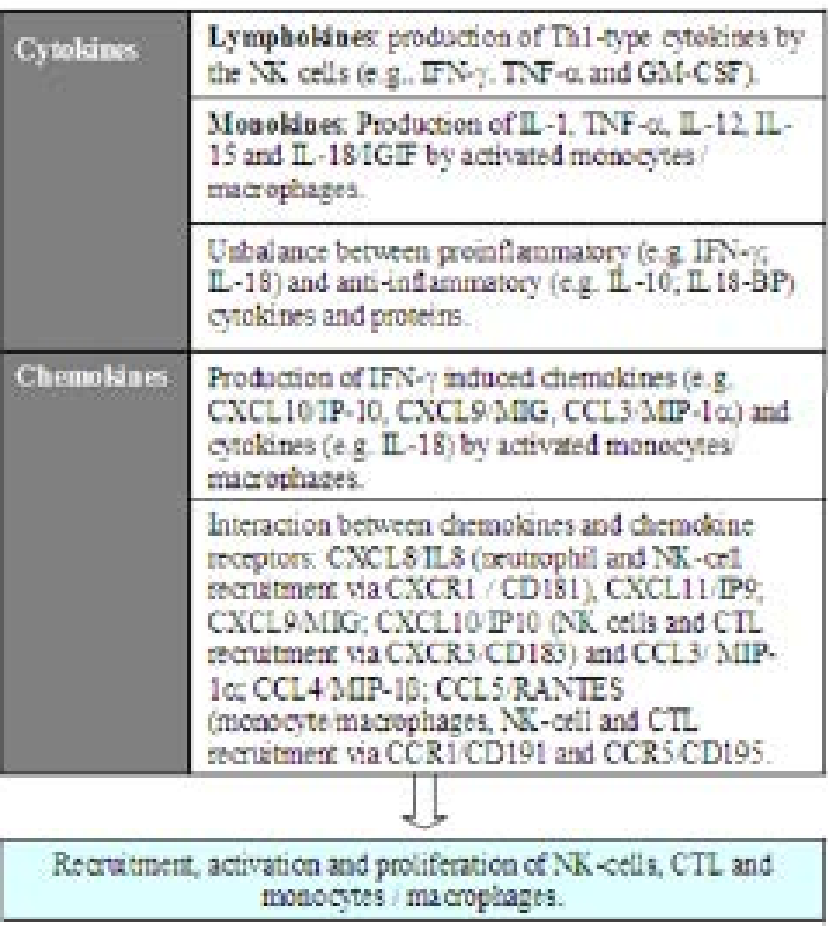

Figure 1: Main molecules involved in disease manifestations typically observed in aggressive NK cell neoplasms.

are divided into 2 major subfamilies, CXC and CC [125]. They regulate leukocyte trafficking by interacting with a subset of 7-transmembrane, $\mathrm{G}$ protein-coupled receptors expressed on the cell surface and play fundamental roles in the development, homeostasis, and function of the immune system; they also have effects on endothelial cells, being involved in angiogenesis or angiostasis. Mature NK cells express a definite repertoire of CXC and CC chemokine receptors, including CXCR1 (CD181), CXCR3 (CD183) and CCR5 (CD195).

NK/T-cell lymphoma cells usually express CXCR3, whose main ligand is CXCL11 (IP9, IFN-gamma inducible protein type 9) [126,127]. Previous studies revealed that ANKL cells are positive for CXCR1 and CCR5, whose major ligands are CXCL8 (interleukin-8, IL-8) and CCL3 (MIP-1alpha, macrophage inflammatory protein type 1 alpha), CCL4 (MIP-1beta) and CCL5 (RANTES, regulated on activation, normal T cell expressed and secreted), respectively [128]. In addition, the serum level of IL-8, MIP-1alpha and MIP-1beta, are significantly elevated in ANKL patients and ANKL cells are positive for IL-8, MIP-1alpha, MIP-1beta and RANTES [129]. Moreover, NKTCL tissues over-express the genes codifying for several cytokines, including CCL2 (monocyte chemotactic protein-1, MCP-1), CCL8 (MCP-2), CCL18 (pulmonary and activation-regulated, PARC), CCL19 (EBI1 ligand chemokine, ELC), CXCL10 (IP10), CXCL12 (stromal cell-derived factor-1, SDF1), and CXCL9 (monokine induced by gamma interferon, MIG) [45]. Altogether, these data would suggest that the chemokine system plays an important role in determining tissue infiltration by NKTCL and inflammatory cells.

\section{Angioinvasion, angiodestruction and tissue damage}

Angioinvasion by the neoplastic cells, angiodestruction and tissue necrosis are characteristic features of NKTCL. Although the exact mechanism is unknown, previous studies revealed that the presence of cytotoxic granule proteins, and the expression of apoptosis related and cell adhesion molecules on the neoplastic NK-cells are relevant factors [129-134].

Cytotoxic molecules and pro-apoptotic proteins: NKTCL overexpress the genes codifying for cytotoxic granule molecules, including granzymes, perforin and cathepsins [45]. In addition, previous studies have shown that NKTCL tumor cells usually express cytotoxic molecules (TIA-1, granzymes and perforin), and that Fas Ligand (FasL) is expressed in the majority of the lymphoma cells, while Fas (CD95) is found both in lymphoma cells and non-neoplastic cells [130]. In addition, ANKCL patients have high serum levels of soluble FasL and ANKCL cells express the FasL protein [129]. Lymphoma cells from cases with angiodestruction also express frequently FasL, Fas, CPP32 (apoptosis-induced cysteine protease 32), the apoptosispromoting protein BAX, and the Ki67/MIB1 (mindbomb E3 ubiquitin protein ligase 1) nuclear proliferating marker, whereas in cases without angiodestruction, the neoplastic cells are frequently positive for FasL and BAX, and negative for Fas, CPP32, and Ki67/MIB1 [131].

Granzyme B-specific serine protease inhibitors, such as SERPINB9 (also known as protease inhibitor type 9, PI9) protect effector cells from their own cytotoxic activity and may participate in tumor escape and loss of expression of PI9 on NKTCL tumor cells was described as a poor prognostic factor $[132,133]$. 
Defensins are small cysteine-rich cationic peptides made by neutrophils with cytotoxic and microbicidal properties, which act by binding to the microbial cell membrane and forming pore-like defects [135]. Defensin beta 1 (DEFB1) is implicated in the resistance of epithelial surfaces to microbial colonization and there is evidence that the DEFB1 gene may function as a tumor suppressor gene, its expression being associated with a large number of cancers [136]. The fact that DEFB1 was found to be overexpressed in NKTCL, would suggest that this cytotoxic protein may also be involved in tissue damage [123].

Cell adhesion molecules: In that concerning Cell Adhesion Molecules (CAM), the neoplastic NK-cells frequently express the CD2, CD11a (lymphocyte function associated molecule type 1, LFA-1), and CD49d (integrin alpha 4) receptors and their ligands, CD58 (lymphocyte function associated molecule type 3, LFA-3, CD54 (intercellular adhesion molecule type 1, ICAM-1) and CD106 (vascular cell adhesion molecule type 1, VCAM-1). The frequency of CD2, CD54, CD58 and CD106+ cases is higher among NKTCL with angiodestruction, as compared with those without [131]. Finally, the integrin subunits alpha2 (CD49b) and alpha M (CD11b) are expressed at a significantly higher level on lymphoma cells in NKTCL with angioinvasion than in those without [134]. The VCAM-1 gene is overexpressed in NKTCL tissues, in comparison to that observed in normal NK cells [45].

\section{Macrophage stimulation and hemophagocytosis}

The Hemophagocytic Syndrome (HS) results from an uncontrolled proliferation and activation of macrophages and usually occurs as a consequence of T- and NK-cell activation, with production of Th1 cytokines, such as IFN-gamma and TNF-alpha [137]. It may result from genetic defects on cytotoxic T-cells (CTL) and NK-cells or rather may be secondary to infections, autoimmune diseases and malignancy, including NK-, T- or B-cell lymphomas. Previous studies have shown that IL-18, also known as interferon-gamma inducing factor (IGIF), is a potent pro-inflammatory cytokine produced by activated monocytes that act on NK-cells and CTL, enhancing the Th1 response and inducing the production of IFN-gamma, a cytokine that is crucial for monocyte/ macrophage activation [138]. This effect is balanced by the action of IL-10, a potent anti-inflammatory cytokine, as well as of the IL-18 binding protein (IL-18BP), the natural inhibitor of IL-18 [139]. There is increasing evidence that both cytokines, IL-18 and IFN-gamma, relate to the genesis of the HS. In fact, patients with lymphoma-associated HS, and especially those with NK/T cell neoplasms, usually have high serum levels of IL-18 and IFN-gamma [33-35,140,141]. In addition, patients with HS usually show a severe imbalance between IL-18 and IL-18BP and recent studies in animal models demonstrate that the IL$18 \mathrm{BP}$ reduces the severity of the HS, by decreasing hemophagocytosis and reversing organ damage $[142,143]$.

Previous studies have shown that NKTCL, as other entities that frequently associate to HS, such as EBV-associated CNKCL, exhibit a high expression of IFN-gamma and certain chemokines, particularly those induced by IFN-gamma, such as IP-10 (CXCL10), MIG (CXCL9), as well as MIP-1alpha (CCL3) [144-146]. The fact that MIP-1alpha causes macrophage chemotaxis and IFN-gamma promotes macrophage activation, would suggest that these molecules may play an important role in the pathogenesis of the HS, by recruiting and activating the macrophages, which are induced to undergo phagocytosis.

\section{Conclusion}

Proteins encoded by EBV genes and non-coding viral RNAs expressed on the infected cells are involved in NK-cell lymphomagenesis and disease progression, which occur as a consequence of multiple EBV-induced oncogenic events. The genes affected include, among others, tumor suppressor genes and oncogenes, as wells as genes involved in cell signal transducer pathways, cell survival and apoptosis, cell cycle control and cell division, as well as cell motility, adhesion and signaling through cytokine networks, many of which are known to be involved in a wide variety of human cancers. These complex molecular and biochemical disturbances, not only justify the aggressiveness of the NK-cell neoplasms, but also explain most of the disease manifestations.

\section{Acknowledgement}

The author thanks to the medical doctors (Catarina Lau, Maria dos Anjos Teixeira), technicians (Ana Helena Santos, Lurdes Oliveira, Maria Luís Queirós Marlene Santos, Marta Gonçalves and Sónia Fonseca) and collaborators (João Rodrigues, Magdalena Leander) of the Cytometry Laboratory for the support concerning NK-cell immunophenotyping and diagnosis of NK-cells lymphoproliferative disorders. She also thanks to the medical doctors who have referred patients for study.

\section{Authors' Information}

$\mathrm{ML}$ is a senior medical doctor, responsible for the Laboratory of Cytometry of the Department of Hematology, Hospital de Santo António, Centro Hospitalar do Porto, Porto, Portugal. The Laboratory of Cytometry is a reference laboratory for the diagnosis of T- and NK-cell disorders. The author has been dedicated to the diagnosis and treatment of T- and NK-cell lymphoproliferative disorders and has already published a large number of papers in this field.

\section{References}

1. Cheung MM, Chan JK, Wong KF (2003) Natural killer cell neoplasms: a distinctive group of highly aggressive lymphomas/leukemias. Semin Hematol 40: 221-232.

2. Suzuki R, Suzumiya J, Nakamura S, Aoki S, Notoya A, et al. (2004) Aggressive natural killer-cell leukemia revisited: large granular lymphocyte leukemia of cytotoxic NK cells. Leukemia 18: 763-770.

3. Hasserjian RP, Harris NL (2007) NK-cell lymphomas and leukemias: a spectrum of tumors with variable manifestations and immunophenotype. Am J Clin Patho 127: 860-868.

4. Oshimi K (2007) Progress in understanding and managing natural killer-cel malignancies. Br J Haematol 139: 532-544.

5. Aozasa K, Takakuwa T, Hongyo T, Yang WI (2008) Nasal NK/T-cell lymphoma: epidemiology and pathogenesis. Int J Hematol 87: 110-117.

6. Liang X, Graham DK (2008) Natural killer cell neoplasms. Cancer 112: 1425 1436.

7. Greer JP, Mosse CA (2009) Natural killer-cell neoplasms. Curr Hematol Malig Rep 4: 245-252.

8. Harabuchi Y, Takahara M, Kishibe K, Moriai S, Nagato T, et al. (2009) Nasa natural killer (NK)/T-cell lymphoma: clinical, histological, virological, and genetic features. Int J Clin Oncol 14: 181-190

9. Kohrt H, Advani R (2009) Extranodal natural killer/T-cell lymphoma: current concepts in biology and treatment. Leuk Lymphoma 50: 1773-1784.

10. Gill H, Liang RH, Tse E (2010) Extranodal natural-killer/t-cell lymphoma, nasal type. Adv Hematol 2010: 627401.

11. Suzuki $R$ (2010) Treatment of advanced extranodal NK/T cell lymphoma, nasaltype and aggressive NK-cell leukemia. Int J Hematol 92: 697-701.

12. Aozasa K, Zaki MA (2011) Epidemiology and pathogenesis of nasal NK/T-cel Iymphoma: a mini-review. ScientificWorldJournal 11: 422-428.

13. Kobayashi S (2011) Natural Killer Cell Leukemia: Diagnosis, Pathogenesis and Treatment. In: Faderl S (Edr.), Novel Aspiration Acute Lymphoblastic Leukemia.

14. Kwong YL (2011) The diagnosis and management of extranodal NK/T-cell lymphoma, nasal-type and aggressive NK-cell leukemia. J Clin Exp Hematop 51: 21-28.

15. Tse E, Kwong YL (2011) Treatment algorithms for mature T-cell and natural killer-cell neoplasms. Future Oncol 7: 1101-1112.

16. Jaccard A, Hermine $O$ (2011) Extranodal natural killer/T-cell lymphoma: advances in the management. Curr Opin Oncol 23: 429-435. 
Citation: Lima M (2013) Aggressive Mature Natural Killer Cell Neoplasms: from Disease Biology to Disease Manifestations. J Blood Disorders Transf 5: 182. doi: 10.4172/2155-9864.1000182

Page 8 of 10

17. Semenzato G, Marino F, Zambello R (2012) State of the art in natural killer cell malignancies. Int J Lab Hematol 34: 117-128.

18. Lima M (2013) Aggressive mature natural killer cell neoplasms: from epidemiology to diagnosis. Orphanet J Rare Dis 8: 95.

19. Au W-Y, Ma S-Y, Chim C-S, Choy C, Loong F, et al. (2005) Clinicopathologic features and treatment outcome of mature T-cell and natural killer-cell lymphomas diagnosed according to the World Health Organization classification scheme: a single center experience of 10 years. Ann Oncol 16: 206-214.

20. Liu J, Song B, Fan T, Huang C, Xie C, et al. (2011) Pathological and clinical characteristics of 1,248 non-Hodgkin's lymphomas from a regional cancer hospital in Shandong, China. Asian Pac J Cancer Prev 12: 3055-3061.

21. Gaal K, Sun NC, Hernandez AM, Arber DA (2000) Sinonasal NK/T-cell lymphomas in the United States. Am J Surg Pathol 24: 1511-1517.

22. Chisté M, Vrotsos E, Zamora C, Martinez A (2013) Chronic lymphocytic leukemia/small lymphocytic lymphoma involving the aortic valve. Ann Diagn Pathol 17: 295-297.

23. Chan JKC, Quintanilla-Martinez L, Ferry JA, Peh S-C (2007) Extranodal NK/Tcell lymphoma, nasal type. In: Swerdlow SH, Campo E, Harris NL, Jaffe ES, Pileri SA, Stein H, et al. (Eds.), WHO classification of tumours of haematopoietic and lymphoid tissues (4th Edn.), International Agency for Research on Cancer (IARC) Press, Lyon, France, pp: 285-258.

24. Chan JKC, Jane ES, Ralfkiaer E, Ko Y-H (2008) Aggressive NK-cell leukaemia. In: Swerdlow SH, Campo E, Harris NL, Jaffe ES, Pileri SA, Stein H, et al., editors. WHO classification of tumours of haematopoietic and lymphoid tissues (4th Edn.), International Agency for Research on Cancer (IARC) Press, Lyon, France, pp: 276-277.

25. Suzuki R, Suzumiya J, Oshimi K (2009) Differences between nasal and extranasal NK/T-cell lymphoma. Blood 113: 6260-6261.

26. Wong KF, Chan JK, Cheung MM, So JC (2001) Bone marrow involvement by nasal NK cell lymphoma at diagnosis is uncommon. Am J Clin Pathol 115: 266 270.

27. Takahashi N, Miura I, Chubachi A, Miura AB, Nakamura S (2001) A clinicopathological study of 20 patients with T/natural killer (NK)-cell lymphomaassociated hemophagocytic syndrome with special reference to nasal and nasal-type NK/T-cell lymphoma. Int J Hematol 74: 303-308.

28. Ruskova A, Thula R, Chan G (2004) Aggressive Natural Killer-Cell Leukemia: report of five cases and review of the literature. Leuk Lymphoma 45: 2427 2438.

29. Oshimi K, Kawa K, Nakamura S, Suzuki R, Suzumiya J, et al. (2005) NK-cell neoplasms in Japan. Hematology 10: 237-245

30. Sino-US Shanghai Leukemia Cooperative Group (2006) [Aggressive NK-cell leukemia: report of nine cases and review of literature]. Zhonghua Xue Ye Xue Za Zhi 27: 116-119.

31. Ryder J, Wang X, Bao L, Gross SA, Hua F, et al. (2007) Aggressive natural killer cell leukemia: report of a Chinese series and review of the literature. Int J Hematol 85: 18-25.

32. Au WY, Weisenburger DD, Intragumtornchai T, Nakamura S, Kim WS, et al. (2009) Clinical differences between nasal and extranasal natural killer/Tcell lymphoma: a study of 136 cases from the International Peripheral T-Cell Lymphoma Project. Blood 113: 3931-3937.

33. Okuda T, Sakamoto S, Deguchi T, Misawa S, Kashima K, et al. (1991) Hemophagocytic syndrome associated with aggressive natural killer cell leukemia. Am J Hematol 38: 321-323.

34. Akashi K, Mizuno S (2000) Epstein-Barr virus-infected natural killer cell leukemia. Leuk Lymphoma 40: 57-66.

35. Kaizu K, Maeda M, Ohkawa T, Hayashida M, Nakajima S, et al. (2004) Marked elevation of soluble fas ligand and cytokine secretion after splenectomy in aggressive natural killer cell leukemia/lymphoma. Leuk Lymphoma 45: 2291 2294.

36. Choi YL, Park JH, Kim WS, Lee DY, Lee JH, et al. (2006) Aggressive NKcell leukaemia associated with reactive haemophagocytic syndrome. Clin Exp Dermatol 31: 83-85.

37. Petterson TE, Bosco AA, Cohn RJ (2008) Aggressive natural killer cell leukemia presenting with hemophagocytic lymphohistiocytosis. Pediatr Blood Cancer 50 : 654-657.
38. Suzuki S, Uozumi K, Utsunomiya A, Ishitsuka K, Masamoto I, et al. (2008) Aggressive NK cell leukaemia after splenectomy: association with CD95resistant memory T-cell proliferation and recalcitrant clinical course of haemophagocytic syndrome. Eur J Haematol 81: 236-241.

39. Han AR, Lee HR, Park BB, Hwang IG, Park S, et al. (2007) Lymphomaassociated hemophagocytic syndrome: clinical features and treatment outcome. Ann Hematol 86: 493-498.

40. Young LS, Rickinson AB (2004) Epstein-Barr virus: 40 years on. Nat Rev Cancer 4: 757-768.

41. Carbone A, Gloghini A, Dotti G (2008) EBV-associated lymphoproliferative disorders: classification and treatment. Oncologist 13: 577-585.

42. Deyrup AT (2008) Epstein-Barr virus-associated epithelial and mesenchymal neoplasms. Hum Pathol 39: 473-483.

43. Mujaj SA, Spanevello MM, Gandhi MK, Nourse JP (2011) Molecular mechanisms influencing NK cell development: implications for NK cell malignancies. Am J Blood Res 1: 34-45.

44. Schmitt C, Sako N, Bagot M, Huang Y, Gaulard P, et al. (2011) Extranodal NK/Tcell lymphoma: toward the identification of clinical molecular targets. J Biomed Biotechnol 2011: 790871

45. Huang Y, de Reyniès A, de Leval L, Ghazi B, Martin-Garcia N, et al. (2010) Gene expression profiling identifies emerging oncogenic pathways operating in extranodal NK/T-cell lymphoma, nasal type. Blood 115: 1226-1237.

46. Wong KF, Zhang YM, Chan JK (1999) Cytogenetic abnormalities in natural killer cell lymphoma/leukaemia--is there a consistent pattern? Leuk Lymphoma 34: $241-250$

47. Zhang Y, Matthiesen P, Harder S, Siebert R, Castoldi G, et al. (2000) A 3-cM commonly deleted region in 6q21 in leukemias and lymphomas delineated by fluorescence in situ hybridization. Genes Chromosomes Cancer 27: 52-58.

48. Sun HS, Su IJ, Lin YC, Chen JS, Fang SY (2003) A 2.6 Mb interval on chromosome 6q25.2-q25.3 is commonly deleted in human nasal natural killer/ T-cell lymphoma. Br J Haematol 122: 590-599.

49. Siu LL, Wong KF, Chan JK, Kwong YL (1999) Comparative genomic hybridization analysis of natural killer cell lymphoma/leukemia. Recognition of consistent patterns of genetic alterations. Am J Pathol 155: 1419-1425.

50. Siu LL, Chan V, Chan JK, Wong KF, Liang R, et al. (2000) Consistent patterns of allelic loss in natural killer cell lymphoma. Am J Pathol 157: 1803-1809.

51. Ko YH, Ree HJ, Kim WS, Choi WH, Moon WS, et al. (2000) Clinicopathologic and genotypic study of extranodal nasal-type natural killer/T-cell lymphoma and natural killer precursor lymphoma among Koreans. Cancer 89: 2106-2116.

52. Ko YH, Choi KE, Han JH, Kim JM, Ree HJ (2001) Comparative genomic hybridization study of nasal-type NK/T-cell lymphoma. Cytometry 46: 85-91.

53. Nakashima Y, Tagawa H, Suzuki R, Karnan S, Karube K, et al. (2005) Genome-wide array-based comparative genomic hybridization of natural killer cell lymphoma/leukemia: different genomic alteration patterns of aggressive NK-cell leukemia and extranodal Nk/T-cell lymphoma, nasal type. Genes Chromosomes Cancer 44: 247-255

54. Yoon J, Ko YH (2003) Deletion mapping of the long arm of chromosome 6 in peripheral T and NK cell lymphomas. Leuk Lymphoma 44: 2077-2082.

55. Karube K, Nakagawa M, Tsuzuki S, Takeuchi I, Honma K, et al. (2011) Identification of FOXO3 and PRDM1 as tumor-suppressor gene candidates in NK-cell neoplasms by genomic and functional analyses. Blood 118: 3195-3204

56. Sokol L (2011) Fox and Blimp in NK-cell lymphoma. Blood 118: 3192-3193.

57. Furukawa-Hibi Y, Kobayashi Y, Chen C, Motoyama N (2005) FOXO transcription factors in cell-cycle regulation and the response to oxidative stress. Antioxid Redox Signal 7: 752-760.

58. Myatt SS, Lam EW (2007) The emerging roles of forkhead box (Fox) proteins in cancer. Nat Rev Cancer 7: 847-859.

59. Möller C, Alfredsson J, Engström M, Wootz H, Xiang Z, et al. (2005) Stem cell factor promotes mast cell survival via inactivation of FOXO3a-mediated transcriptional induction and MEK-regulated phosphorylation of the proapoptotic protein Bim. Blood 106: 1330-1336.

60. You H, Pellegrini M, Tsuchihara K, Yamamoto K, Hacker G, et al. (2006) FOXO3a-dependent regulation of Puma in response to cytokine/growth factor withdrawal. J Exp Med 203: 1657-1663. 
Citation: Lima M (2013) Aggressive Mature Natural Killer Cell Neoplasms: from Disease Biology to Disease Manifestations. J Blood Disorders Transf 5: 182. doi: 10.4172/2155-9864.1000182

61. Skurk C, Maatz H, Kim HS, Yang J, Abid MR, et al. (2004) The Akt-regulated forkhead transcription factor FOXO3a controls endothelial cell viability through modulation of the caspase-8 inhibitor FLIP. J Biol Chem 279: 1513-1525.

62. Chung YM, Park SH, Tsai WB, Wang SY, Ikeda MA, et al. (2012) FOXO3 signalling links ATM to the p53 apoptotic pathway following DNA damage. Nat Commun 3: 1000 .

63. Storz P (2011) Forkhead homeobox type $O$ transcription factors in the responses to oxidative stress. Antioxid Redox Signal 14: 593-605.

64. Smith MA, Maurin M, Cho HI, Becknell B, Freud AG, et al. (2010) PRDM1/ Blimp-1 controls effector cytokine production in human NK cells. J Immuno 185: 6058-6067.

65. Küçük C, lqbal J, Hu X, Gaulard P, De Leval L, et al. (2011) PRDM1 is a tumo suppressor gene in natural killer cell malignancies. Proc Natl Acad Sci U S A 108: 20119-20124

66. Iqbal J, Kucuk C, Deleeuw RJ, Srivastava G, Tam W, et al. (2009) Genomic analyses reveal global functional alterations that promote tumor growth and novel tumor suppressor genes in natural killer-cell malignancies. Leukemia 23 : 1139-1151.

67. Schmitz R, Hansmann ML, Bohle V, Martin-Subero Jl, Hartmann S, et al. (2009) TNFAIP3 (A20) is a tumor suppressor gene in Hodgkin lymphoma and primary mediastinal B cell lymphoma. J Exp Med 206: 981-989.

68. Küçük C, Hu X, Iqbal J, Gaulard P, Klinkebiel D, et al. (2013) HACE1 is a tumor suppressor gene candidate in natural killer cell neoplasms. Am J Pathol 182: $49-55$

69. Ando M, Sato Y, Takata K, Nomoto J, Nakamura S, et al. (2013) A20 (TNFAIP3) deletion in Epstein-Barr virus-associated lymphoproliferative disorders/ Iymphomas. PLoS One 8: e56741.

70. Verstrepen L, Verhelst K, van Loo G, Carpentier I, Ley SC, et al. (2010) Expression, biological activities and mechanisms of action of A20 (TNFAIP3) Biochem Pharmacol 80: 2009-2020.

71. Shembade N, Harhaj EW (2012) Regulation of NF- KB signaling by the A20 deubiquitinase. Cell Mol Immunol 9: 123-130.

72. Tang D, Xiang Y, De Renzis S, Rink J, Zheng G, et al. (2011) The ubiquitin ligase HACE1 regulates Golgi membrane dynamics during the cell cycle. Nat Commun 2: 501 .

73. Castillo-Lluva S, Tan CT, Daugaard M, Sorensen PH, Malliri A (2013) The tumour suppressor HACE1 controls cell migration by regulating Rac1 degradation. Oncogene 32: 1735-1742.

74. Ng SB, Selvarajan V, Huang G, Zhou J, Feldman AL, et al. (2011) Activated oncogenic pathways and therapeutic targets in extranodal nasal-type NK/T cell lymphoma revealed by gene expression profiling. J Pathol 223: 496-510.

75. Levine AJ, Momand J, Finlay CA (1991) The p53 tumour suppressor gene. Nature 351: 453-456.

76. Hollstein M, Sidransky D, Vogelstein B, Harris CC (1991) p53 mutations in human cancers. Science 253: 49-53.

77. Greenblatt MS, Bennett WP, Hollstein M, Harris CC (1994) Mutations in the p53 tumor suppressor gene: clues to cancer etiology and molecular pathogenesis. Cancer Res 54: 4855-4878.

78. Li T, Hongyo T, Syaifudin M, Nomura T, Dong Z, et al. (2000) Mutations of the p53 gene in nasal NK/T-cell lymphoma. Lab Invest 80: 493-499.

79. Hoshida Y, Hongyo T, Jia X, He Y, Hasui K, et al. (2003) Analysis of p53, K-ras, $\mathrm{c}$-kit, and beta-catenin gene mutations in sinonasal NK/T cell lymphoma in northeast district of China. Cancer Sci 94: 297-301.

80. Takahara M, Kishibe K, Bandoh N, Nonaka S, Harabuchi Y (2004) P53, N- and $\mathrm{K}-\mathrm{Ras}$, and beta-catenin gene mutations and prognostic factors in nasal NK/Tcell lymphoma from Hokkaido, Japan. Hum Pathol 35: 86-95.

81. Hongyo T, Hoshida Y, Nakatsuka S, Syaifudin M, Kojya S, et al. (2005) p53, $\mathrm{K}$-ras, c-kit and beta-catenin gene mutations in sinonasal NK/T-cell lymphoma in Korea and Japan. Oncol Rep 13: 265-271.

82. Quintanilla-Martinez L, Kremer M, Keller G, Nathrath M, Gamboa-Dominguez A, et al. (2001) p53 Mutations in nasal natural killer/T-cell lymphoma from Mexico: association with large cell morphology and advanced disease. Am J Pathol 159: 2095-2105.
83. Stiewe T, Pützer BM (2002) Role of p73 in malignancy: tumor suppressor or oncogene? Cell Death Differ 9: 237-245.

84. Siu LL, Chan JK, Wong KF, Kwong YL (2002) Specific patterns of gene methylation in natural killer cell lymphomas : p73 is consistently involved. Am J Pathol 160: 59-66.

85. Hongyo T, Li T, Syaifudin M, Baskar R, Ikeda H, et al. (2000) Specific c-kit mutations in sinonasal natural killer/T-cell lymphoma in China and Japan. Cancer Res 60: 2345-2347.

86. Albihn A, Johnsen JI, Henriksson MA (2010) MYC in oncogenesis and as a target for cancer therapies. Adv Cancer Res 107: 163-224.

87. Klapproth K, Wirth T (2010) Advances in the understanding of MYC-induced lymphomagenesis. Br J Haematol 149: 484-497.

88. Kawamata N, Inagaki N, Mizumura S, Sugimoto KJ, Sakajiri S, et al. (2005) Methylation status analysis of cell cycle regulatory genes (p16INK4A p15INK4B, p21Waf1/Cip1, p27Kip1 and p73) in natural killer cell disorders. Eu J Haematol 74: 424-429.

89. Mahadevan D, Spier C, Della Croce K, Miller S, George B, et al. (2005) Transcript profiling in peripheral T-cell lymphoma, not otherwise specified, and diffuse large B-cell lymphoma identifies distinct tumor profile signatures. Mol Cancer Ther 4: 1867-1879.

90. Bos JL (1989) ras oncogenes in human cancer: a review. Cancer Res 49: 4682 4689 .

91. Valenta T, Hausmann G, Basler K (2012) The many faces and functions of $\hat{I}^{2}$ catenin. EMBO J 31: 2714-2736.

92. Ge X, Wang X (2010) Role of Wnt canonical pathway in hematological malignancies. J Hematol Oncol 3: 33

93. Smith J, Tho LM, Xu N, Gillespie DA (2010) The ATM-Chk2 and ATR-Chk1 pathways in DNA damage signaling and cancer. Adv Cancer Res 108: 73-112.

94. Liu A, Takakuwa T, Luo WJ, Fujita S, Aozasa K (2006) Alterations in ATR in nasal NK/T-cell lymphoma and chronic active Epstein-Barr virus infection. Cancer Sci 97: 605-610.

95. Darnell JE Jr, Kerr IM, Stark GR (1994) Jak-STAT pathways and transcriptiona activation in response to IFNs and other extracellular signaling proteins. Science 264: 1415-1421.

96. Coppo P, Gouilleux-Gruart V, Huang Y, Bouhlal H, Bouamar H, et al. (2009) STAT3 transcription factor is constitutively activated and is oncogenic in nasaltype NK/T-cell lymphoma. Leukemia 23: 1667-1678.

97. Tsutsui $M$, Yasuda $H$, Suto $H$, Imai $H$, Isobe $Y$, et al. (2010) Frequent STAT3 activation is associated with $\mathrm{Mcl}-1$ expression in nasal NK-cell lymphoma. Int $J$ Lab Hematol 32: 419-426.

98. Guruharsha KG, Kankel MW, Artavanis-Tsakonas S (2012) The Notch signalling system: recent insights into the complexity of a conserved pathway. Nat Rev Genet 13: 654-666.

99. Zhang Y, Ohyashiki JH, Takaku T, Shimizu N, Ohyashiki K (2006) Transcriptional profiling of Epstein-Barr virus (EBV) genes and host cellular genes in nasal NK T-cell lymphoma and chronic active EBV infection. Br J Cancer 94: 599-608.

100. Jost PJ, Ruland J (2007) Aberrant NF-kappaB signaling in lymphoma: mechanisms, consequences, and therapeutic implications. Blood 109: 2700 2707.

101. Iqbal J, Weisenburger DD, Chowdhury A, Tsai MY, Srivastava G, et al. (2011) Natural killer cell lymphoma shares strikingly similar molecular features with a group of non-hepatosplenic ?d T-cell lymphoma and is highly sensitive to a novel aurora kinase A inhibitor in vitro. Leukemia 25: 348-358.

102. Shen L, Liang AC, Lu L, Au WY, Kwong YL, et al. (2002) Frequent deletion of Fas gene sequences encoding death and transmembrane domains in nasal natural killer/T-cell lymphoma. Am J Pathol 161: 2123-2131.

103. Takakuwa T, Dong Z, Nakatsuka S, Kojya S, Harabuchi Y, et al. (2002) Frequent mutations of Fas gene in nasal NK/T cell lymphoma. Oncogene 21: 4702-4705

104. Bischoff JR, Plowman GD (1999) The Aurora/Ipl1p kinase family: regulators of chromosome segregation and cytokinesis. Trends Cell Biol 9: 454-459.

105. Fuller BG, Stukenberg PT (2009) Cell division: righting the check. Curr Biol 19: R550-553. 
Citation: Lima M (2013) Aggressive Mature Natural Killer Cell Neoplasms: from Disease Biology to Disease Manifestations. J Blood Disorders Transf 5: 182. doi: 10.4172/2155-9864.1000182

Page 10 of 10

106. Katayama H, Sasai K, Kawai H, Yuan ZM, Bondaruk J, et al. (2004) Phosphorylation by aurora kinase A induces Mdm2-mediated destabilization and inhibition of p53. Nat Genet 36: 55-62.

107. Sakurai T, Kudo M (2011) Signaling pathways governing tumor angiogenesis Oncology 81 Suppl 1: 24-29.

108. Tang QL, Liu WP, Zhang WY, Yang F, He MX, et al. (2006) [Expression of CYR61 and VEGF in extranodal nasal-type NK/T cell lymphoma and their significances]. Zhonghua Xue Ye Xue Za Zhi 27: 661-665.

109. Li T, Liu D, Zhang F (2001) [Expression and significance of CD44 and angiogenic growth factor in nasal NK/T cells lymphoma]. Zhonghua Yi Xue Za Zhi 81: 776-778.

110. Chen YP, Chang KC, Su WC, Chen TY (2008) The expression and prognostic significance of platelet-derived growth factor receptor alpha in mature T- and natural killer-cell lymphomas. Ann Hematol 87: 985-990.

111. Boulland ML, Meignin V, Leroy-Viard K, Copie-Bergman C, Brière J, et al (1998) Human interleukin-10 expression in T/natural killer-cell lymphomas: association with anaplastic large cell lymphomas and nasal natural killer-cell lymphomas. Am J Pathol 153: 1229-1237.

112. Xu ZG, Iwatsuki K, Oyama N, Ohtsuka M, Satoh M, et al. (2001) The latency pattern of Epstein-Barr virus infection and viral IL-10 expression in cutaneous natural killer/T-cell lymphomas. Br J Cancer 84: 920-925

113. Nagato T, Kobayashi H, Kishibe K, Takahara M, Ogino T, et al. (2005) Expression of interleukin-9 in nasal natural killer/T-cell lymphoma cell lines and patients. Clin Cancer Res 11: 8250-8257.

114. Itoh Y, Nagase $H$ (2002) Matrix metalloproteinases in cancer. Essays Biochem 38: 21-36.

115. Sbardella D, Fasciglione GF, Gioia M, Ciaccio C, Tundo GR, et al. (2012) Human matrix metalloproteinases: an ubiquitarian class of enzymes involved in several pathological processes. Mol Aspects Med 33: 119-208.

116. Bauvois B (2012) New facets of matrix metalloproteinases MMP-2 and MMP9 as cell surface transducers: outside-in signaling and relationship to tumor progression. Biochim Biophys Acta 1825: 29-36.

117. Murphy G (2011) Tissue inhibitors of metalloproteinases. Genome Biol 12: 233

118. Nomura T, Katunuma $N$ (2005) Involvement of cathepsins in the invasion metastasis and proliferation of cancer cells. J Med Invest 52: 1-9.

119. Mohamed MM, Sloane BF (2006) Cysteine cathepsins: multifunctional enzymes in cancer. Nat Rev Cancer 6: 764-775.

120. Meneses-García A, Betancourt AM, Abarca JH, Montes AB, Roa LS, et al (2008) Expression of the metalloproteases MMP-1, MMP-2, MMP-3, MMP-9, MMP-11, TIMP-1 and TIMP-2 in angiocentric midfacial lymphomas. World J Surg Oncol 6: 114

121. Sakata K, Satoh M, Someya M, Asanuma H, Nagakura H, et al. (2004) Expression of matrix metalloproteinase 9 is a prognostic factor in patients with non-Hodgkin lymphoma. Cancer 100: 356-365.

122. Sakata K, Someya M, Omatsu M, Asanuma H, Hasegawa T, et al. (2007) The enhanced expression of the matrix metalloproteinase 9 in nasal NK/T-cel lymphoma. BMC Cancer 7: 229.

123. Yu JB, Zhang YC, Yang QP, Wang XL, Tang Y, et al. (2013) Invasion-associated genes identified by gene expression profiling in extranodal natural killer/T-cell lymphoma, nasal type. Leuk Lymphoma 54: 90-98.

124. Hasui K, Wang J, Jia X, Tanaka M, Nagai T, et al. (2011) Enhanced Autophagy and Reduced Expression of Cathepsin D Are Related to Autophagic Cell Death in Epstein-Barr Virus-Associated Nasal Natural Killer/T-Cell Lymphomas: An Immunohistochemical Analysis of Beclin-1, LC3, Mitochondria (AE-1), and Cathepsin D in Nasopharyngeal Lymphomas. Acta Histochem Cytochem 44: 119-131.

125.Zlotnik A, Yoshie O (2012) The chemokine superfamily revisited. Immunity 36 705-716.

126. Schwartz EJ, Molina-Kirsch H, Zhao S, Marinelli RJ, Warnke RA, et al. (2008) Immunohistochemical characterization of nasal-type extranodal NK/T-cell lymphoma using a tissue microarray: an analysis of 84 cases. Am J Clin Pathol 130: $343-351$

127. Yagi H, Seo N, Ohshima A, Itoh T, Itoh N, et al. (2006) Chemokine receptor expression in cutaneous T cell and NK/T-cell lymphomas: immunohistochemical staining and in vitro chemotactic assay. Am J Surg Pathol 30: 1111-1119.

128. Makishima H, Ito T, Asano N, Nakazawa H, Shimodaira S, et al. (2005) Significance of chemokine receptor expression in aggressive NK cell leukemia. Leukemia 19: 1169-1174.

129. Makishima H, Ito T, Momose K, Nakazawa H, Shimodaira S, et al. (2007) Chemokine system and tissue infiltration in aggressive NK-cell leukemia. Leuk Res 31: 1237-1245.

130. Ohshima K, Suzumiya J, Shimazaki K, Kato A, Tanaka T, et al. (1997) Nasa T/NK cell lymphomas commonly express perforin and Fas ligand: important mediators of tissue damage. Histopathology 31: 444-450.

131. Takeshita M, Yamamoto M, Kikuchi M, Kimura N, Nakayama J, et al. (2000) Angiodestruction and tissue necrosis of skin-involving CD56+ NK/T-cell lymphoma are influenced by expression of cell adhesion molecules and cytotoxic granule and apoptosis-related proteins. Am J Clin Pathol 113: 201-211.

132. Bladergroen BA, Meijer CJ, ten Berge RL, Hack CE, Muris JJ, et al. (2002) Expression of the granzyme $B$ inhibitor, protease inhibitor 9 , by tumor cells in patients with non-Hodgkin and Hodgkin lymphoma: a novel protective mechanism for tumor cells to circumvent the immune system? Blood 99: 232-237.

133. Bossard C, Belhadj K, Reyes F, Martin-Garcia N, Berger F, et al. (2007) Expression of the granzyme B inhibitor PI9 predicts outcome in nasal NK/Tcell lymphoma: results of a Western series of 48 patients treated with firstline polychemotherapy within the Groupe d'Etude des Lymphomes de l'Adulte (GELA) trials. Blood 109: 2183-2189.

134. Liu A, Nakatsuka S, Yang WI, Kojya S, Aozasa K (2005) Expression of cell adhesion molecules and chemokine receptors: angioinvasiveness in nasal NK/T-cell lymphoma. Oncol Rep 13: 613-620.

135. Pinheiro da Silva F, Machado MC (2012) Antimicrobial peptides: clinical relevance and therapeutic implications. Peptides 36: 308-314

136. Prado-Montes de Oca E (2010) Human beta-defensin 1: a restless warrio against allergies, infections and cancer. Int J Biochem Cell Biol 42: 800-804.

137. Larroche C, Mouthon L (2004) Pathogenesis of hemophagocytic syndrome (HPS). Autoimmun Rev 3: 69-75.

138. Dinarello CA (2000) Interleukin-18, a proinflammatory cytokine. Eur Cytokine Netw 11: 483-486.

139. Dinarello CA (2000) Targeting interleukin 18 with interleukin 18 binding protein Ann Rheum Dis 59 Suppl 1: i17-20

140. Takada H, Nomura A, Ohga S, Hara T (2001) Interleukin-18 in hemophagocytic lymphohistiocytosis. Leuk Lymphoma 42: 21-28.

141. Ohno T, Ueda Y, Nagai K, Takahashi T, Konaka Y, et al. (2003) The serum cytokine profiles of lymphoma-associated hemophagocytic syndrome: a comparative analysis of B-cell and T-cell/natural killer cell lymphomas. Int J Hematol 77: 286-294.

142. Mazodier K, Marin V, Novick D, Farnarier C, Robitail S, et al. (2005) Severe imbalance of IL-18/IL-18BP in patients with secondary hemophagocytic syndrome. Blood 106: 3483-3489.

143. Chiossone L, Audonnet S, Chetaille B, Chasson L, Farnarier C, et al. (2012) Protection from inflammatory organ damage in a murine model of hemophagocytic lymphohistiocytosis using treatment with $\mathrm{IL}-18$ binding protein. Front Immunol 3: 239

144. Teruya-Feldstein J, Jaffe ES, Burd PR, Kanegane H, Kingma DW, et al. (2007) The role of Mig, the monokine induced by interferon-gamma, and IP-10, the interferon-gamma-inducible protein-10, in tissue necrosis and vascular damage associated with Epstein-Barr virus-positive lymphoproliferative disease. Blood 90: 4099-4105.

145. Teruya-Feldstein J, Setsuda J, Yao X, Kingma DW, Straus S, et al. (1999) MIP1 alpha expression in tissues from patients with hemophagocytic syndrome. Lab Invest 79: 1583-1590.

146. Ohshima K, Karube K, Hamasaki M, Tutiya T, Yamaguchi T, et al. (2003) Differential chemokine, chemokine receptor and cytokine expression in Epstein-Barr virus-associated lymphoproliferative diseases. Leuk Lymphoma 44: $1367-1378$ 